\title{
Analysis of socioeconomic status and other factors affecting patient-graft survival in patients undergoing liver transplantation
}

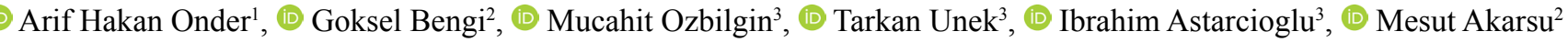 \\ ${ }^{1}$ Department of Internal Medicine, Dokuz Eylul University, Izmir, Turkey; ${ }^{2}$ Division of Gastroenterology, Department of Internal Medicine, Dokuz Eylul University, \\ Izmir, Turkey; ${ }^{3}$ Department of General Surgery, Dokuz Eylul University, Izmir,Turkey
}

\begin{abstract}
Background and Aim: Liver transplantation is performed in increasing numbers due to advances in surgical techniques and the introduction of diverse immunosuppressive drugs. The present study aims to analyze the effects of socioeconomic status and education level on patient and graft survival, in addition to all these factors.

Material and Methods: All patients aged 18 years and above who underwent consecutive liver transplantation at the Liver Transplantation Unit of Department of General Surgery at the Dokuz Eylül University Hospital and whose data were available were included in this study.

Results: Incompliance was noted in $68.3 \%$ of the 278 patients. On the other hand, patient compliance did not have a significant effect on graft and patient survival. However, decreased levels in the parameters, such as education status, vocational status and socioeconomic status, were found to be correlated with patient compliance. A significant correlation was not found between these factors and patient and graft survival.

Conclusion: Although a direct effect of socioeconomic status on patient and graft survival could not be shown the significant association of vocational status and education status which determine socioeconomic level with parameters other than patient and graft survival may affect the success of liver transplants.
\end{abstract}

Keywords: Liver transplantation; patient compliance; patient survival.

\section{Introduction}

Liver transplantation, which is a life-saving treatment of chronic and irreversible liver diseases, is performed in increasing numbers due to the advances in surgical techniques and the introduction of diverse immunosuppressive drugs. ${ }^{[1]}$ Globally, one-year and five-year survival rates following liver transplantation are over $90 \%$ and $70 \%$, respectively. ${ }^{[2]}$ Prolonged survival arises from advanced surgical techniques, improvements in finding and preserving organs, advances in immunosuppressive therapies, and maybe, the most important among these, patient selection and timing. The major problem in liver transplantation is the difficulty of finding organs.

Received: December 26, 2019; Accepted: January 11, 2020; Available online: January 20, 2020

Corresponding author: Goksel Bengi; Dokuz Eylul Universites Hastanesi, Gastroenteroloji Bolumu, Inciralti 35000, Izmir, Turkey

Phone: +90 23241237 13; e-mail: goksel.bengi@deu.edu.tr

๑) Copyright 2020 by Hepatology Forum - Available online at www.hepatologyforum.org
Multiple factors determine patient and graft survival. Other than factors, such as donor characteristics, characteristics related to surgery, post-transplant complications, immunosuppressive drugs used and patient compliance, are doubtlessly the most important factors. Insufficient patient compliance both decreases the quality of life and shortens life span. ${ }^{[3]}$ Rejection and even graft loss can be observed because of the patient compliance. ${ }^{[4]}$ With the available evidence, $50 \%$ of late acute rejection and $15 \%$ of graft loss have been reported to develop because of patient compliance again. ${ }^{[5]}$ Patient incompliance has been held responsible for $25 \%$ of the deaths following liver transplantation. ${ }^{[3]}$ While initially patient compliance was a term expressing the compliance of patients to the prescription, ${ }^{[6]}$ it now includes not only drug compliance but at the same time factors like consistency in attending clinical appointments, compliance to performing the work up requested by the doctor and prompt reporting of arising complications. ${ }^{[7]}$ Patient incompliance is associated with individual characteristics of the patients, their awareness of the severity of their disease, communication with their doctors and the presence or absence of family support. ${ }^{[8]}$

It has been reported that socioeconomic status is an important determinant of incompliance to medical therapy. ${ }^{[9]}$ Educational and socioeconomic status of the patients has been associated with the delayed application for transplantation, difficulties in the management of posttransplant patients and incompliance with medical treatment. Patient compliance has a central role in solid organ transplantation and includes drug intake, diet and lifestyle changes. ${ }^{[4]}$ Although the places where liver transplant recipients live are consistent with their socioeconomic status, it is also important that they live in places where they can reach and meet their needs, primarily those concerning their health. In addition to the difficulties encountered in obtaining the liver, the selection of patients who will undergo liver transplantation is also important. Among the factors that influence patient and graft survival after transplantation, the socioeconomic and educational status of the recipient may have to be taken into consideration in patient selection before transplantation. The present study aims to analyze the factors and primarily socioeconomic and educational status, affecting patient and graft survival.

\section{Materials and Methods}

\section{Patients}

All patients aged 18 years and above who underwent consecutive liver transplantation at the Liver Transplantation Unit of Department of General Surgery at Dokuz Eylül University Hospital between 2006 and 2011 
and whose data were available were included in this study. Patients' diagnoses, treatments, follow up data and donor characteristics were reached from the computerized automation system used at our hospital, hospital archive files, patient follow up charts of liver transplantation unit, the patient follows up forms of liver outpatient clinic and by making phone calls. Three hundred eighteen liver transplantations were performed at the Liver Transplantation Unit between January 2006 and December 2011. When re-transplantations were excluded, a total of 313 patients had undergone liver transplantation. When patients younger than 18 years and without accessible records were excluded from this study, records of the remaining 278 patients were retrospectively reviewed.

Consent was obtained from the Dokuz Eylül University Hospital Ethics Committee of Clinical Research dating 27.09.2012 and with protocol number 740-GOA and with 2012/31-01 decision number. Also, informed consent was obtained for the use of file data from the patients included in this study.

\section{Methods}

\section{Socio-demographic Data}

Patients' socio-demographic data, age gender, BMI, date of surgery, comorbid diseases, smoking and alcohol use, place of birth and residence, educational and vocational status and social security were retrospectively analyzed and recorded.

After places of birth and residence were separated according to the developmental level of the regions, provinces where the patients were born and lived were classified according to developmental criteria regarding social, economic and workforce measures and were recorded. When the criteria mentioned above were applied, the provinces were separated into five levels stated below. Provinces where the patients were born or lived were grouped according to this table. ${ }^{[10]}$ The places where the patients were born or lived were separated as the city center, county and village/small town and the provincial classifications were corrected according to these criteria. The developmental level of the province was reduced by 1 point if the individual lived in a county and by 2 points if the individual lived in a village or small town. As a result of this classification, socioeconomic data of the places born and lived were corrected by separating them into seven levels from high to low. Following this grouping, the places were stratified as high socioeconomic level in the first two levels and low socioeconomic level in the following levels.

When individuals were evaluated according to educational status, they were separated into groups from 1 to 6 regarding their educational level recorded in the system, and these groups were defined as being illiterate, elementary school graduate, junior high school graduate, high school graduate, vocational school graduate and university graduate. Following this grouping, the first three levels were stratified as low, and the following levels as high educational levels. To evaluate individuals according to their vocational status, occupations of the individuals were recorded, and they were classified into 10 major groups. ${ }^{[1]}$ Following this classification, the first five groups were stratified as low and the following groups as high vocational groups.

Hollingshead index (HI), which is calculated according to the educational and occupational groups and frequently used as an indicator of socioeconomic status, was applied to the data and was separated into four groups by applying the formula of $\mathrm{HI}=$ Educational status $\mathrm{x} 3+$ Vocational status $\times{ }^{5 .{ }^{[12]}}$ Provided that the minimum score was 8 and the maximum score was 62 , the $1^{\text {st }}$ group had a score of less than $21,2^{\text {nd }}$ group had a score between 21 and $34,3^{\text {rd }}$ group had a score between 34 and 48 and $4^{\text {th }}$ group had a score of 48 and higher. The first two of these four groups calculated thus were stratified into low and the following groups into high socioeconomic status.

\section{Primary Disease Data}

The primary diseases that cause liver failure were determined and recorded. These etiologic diseases and primarily the more frequent causes were collected under five major headings as follows: Hepatitis $\mathrm{B}$, hepatitis C, ethylism, cryptogenic and other causes. Hepatocellular carcinoma (HCC), which is associated with some of these etiologic diseases, was recorded under a separate data group.

\section{Pre-transplant Scoring Data}

Child-Pugh scoring, MELD scoring and American United Network for Organ Sharing, which determine the prognosis and degree of insufficiency in patients with liver failure, were used.

\section{Data about the Operation}

Surgery time, cold ischemia time, reperfusion syndrome and perioperative complication data about the liver transplantation surgery were recorded.

\section{Donor Data}

Data about the donor were recorded after analyzing gender, age and donor type, which shows whether the donor was live or cadaver.

\section{Patient Follow up Data}

Primarily follow up durations were determined in the follow-up data of liver transplant recipients. Time elapsed between surgery date and final control visit was calculated in days and months. Complications developing after liver transplantation were grouped as surgical, metabolic, neurologic, cardiac, infectious, vascular, rheumatologic, gastrointestinal, neoplastic, biliary complications, incisional hernia and preservation damage. Immunosuppressive drugs and their combinations used by liver transplant recipients were examined. Changes made in immunosuppressive drugs because of adverse effects or lack of efficacy during follow up of transplant recipients were recorded.

\section{Patient Compliance Data}

Compliance with the given drugs, control visits and lifestyle changes were analyzed under patient compliance in liver transplant recipients. Drug incompliances developing due to patient-related causes other than drug-related adverse events or lack of efficacy were recorded as incompliances to drugs. Loss of control visits in the first 24 months and after 24 months was analyzed and the number of visit losses were separated as 1 and $\geq 2$ visits and recorded as incompliance to control visits. Regarding compliance with lifestyle changes, weight gain, post-transplant smoking and alcohol intake were analyzed. Conditions of recipients regarding work activity following transplantation were noted.

\section{Data about the Recurrence of Primary Disease}

Recurrence of primary disease in the recipients was analyzed. As a 
result of liver biopsies and serologic examinations performed during follow up of liver transplant patients, recurrences were separated as recurrences with serology positive pathologic diagnosis and serology negative pathologic diagnosis. During this examination, liver transplant patients with persistent positive serology after transplantation were also noted and recorded.

\section{Patient and Graft Endpoint Data}

Endpoint data were death and rejection. The rejection was separated into groups as clinical, pathologic and clinicopathologic. Clinical pathologic data were recorded by also including data showing prior pulsed steroid use and its frequency present in the records. Regarding pathologic rejection, rejection results stated in liver biopsy samples reported by Department of Pathology at the Dokuz Eylül University Hospital were recorded. The clinicopathologic rejection was accepted as performing a biopsy to the transplanted liver in patients clinically thought to undergo rejection, reporting of the pathology report as rejection and administration of pulsed steroid if the patient was clinically suitable.

Time to death following transplantation was recorded. Causes of death were identified and grouped. When it was noted that deaths occurred more commonly at an early period, thinking that it could yield globally erroneous results in the evaluation of patient compliance, cases followed for at least 100 days were isolated and recorded.

\section{Statistical Analysis}

Analysis of study data was carried out using SPSS for Windows version 16.0. The distribution of the variables was assessed using KolmogorovSmirnov normality tests and histograms. Continuous data were presented as mean and \pm standard deviation. Taking into account sample sizes, distributions and data characteristics, the $\mathrm{X}^{2}$ test was used for the comparison of differences between categorical variables. Yates' correction was used for enhancing confidence. If the value expected from the analysis results was small, Fisher's exact test was used instead of the $\mathrm{X}^{2}$ test. Mann-Whitney U test was used for the correlation between the identified groups and data expressed in mean values. Data compared with the groups were presented in tables together with p-values. Kaplan-Meier and Cox regression tests were used for the evaluation of overall and progression-free survival outcomes. Logistic regression test was used for prognostic and predictive factors. Two-ended $\mathrm{p} \leq 0.05$ was considered significant for all analyses.

\section{Results}

\section{Demographic Characteristics of the Patients}

Two hundred seventy-eight patients were included in this study, and their data were analyzed. One hundred ninety patients $(68.3 \%)$ were male, and $88(31.7 \%)$ were female. Median age of all patients was 49.0 (18-66). Median body mass index (BMI) was 25.65 (16.1-40), and the median BMI of male patients was $25.60(18.5-38.2)$ and that of females was $25.75(16.1-40)(\mathrm{p}=0.649)$. BMI was divided into three groups as 18.5-24.9 $(\mathrm{n}=112,40.3 \%), 25-29.9(\mathrm{n}=124,44.6 \%)$ and $\geq 30(\mathrm{n}=42$, $15.1 \%)$. Patients with comorbidities had higher BMI values $(\mathrm{p}<0.001)$. Similarly, patients with complications also had significantly higher BMI values $(p=0.007)$. Patient compliance was less in the patients with high BMI ( $\mathrm{p}=0.022)$, and this was associated with failure to control weight in the case of incompliance with lifestyle changes $(p<0.001)$.

Comorbidities were present in $56.8 \%$ of the patients $(n=158)$. The most

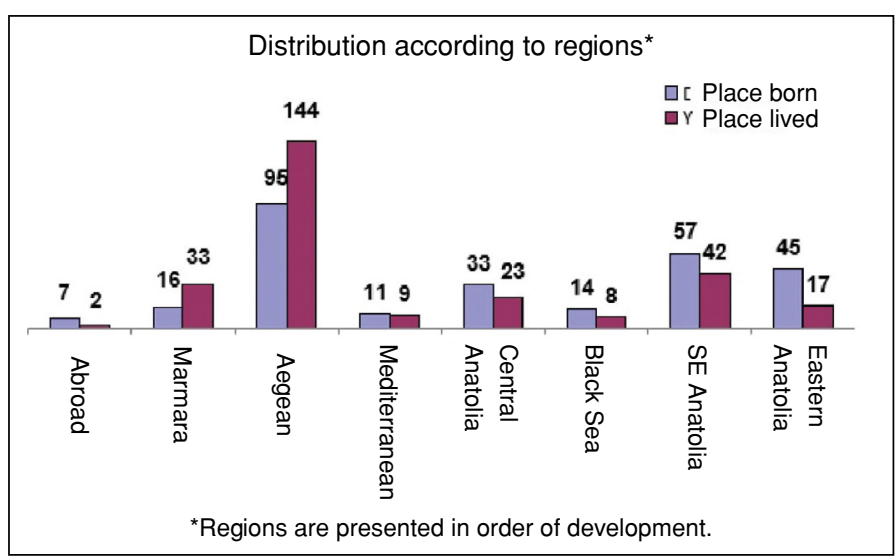

Figure 1. Distribution of patient numbers according to regions.

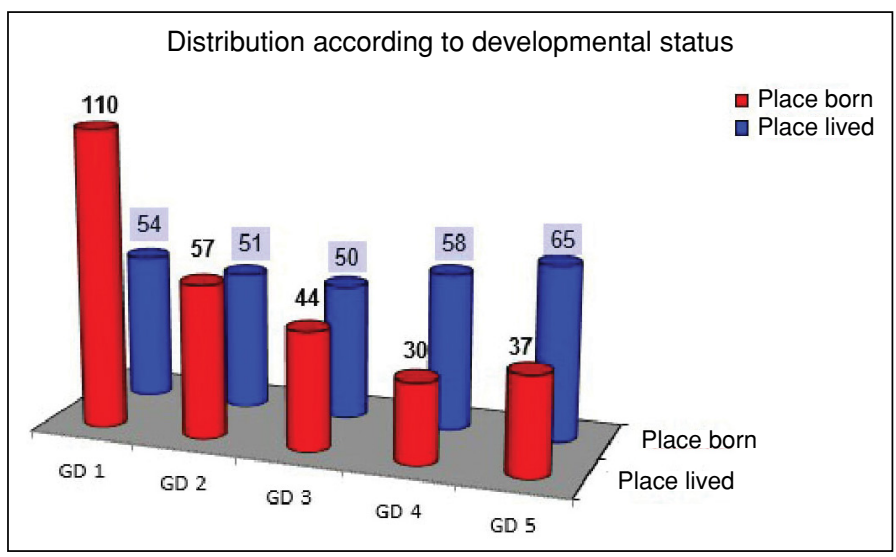

Figure 2. Distribution of places born and lived according to developmental status.

commonly seen comorbid diseases were HT in $74.7 \%(n=118), D M$ in $37.3 \%(n=59)$ and HL in $12.7 \%(n=20)$.

Before the transplantation, $61.5 \%$ of the patients $(n=171)$ smoked and $30.6 \%(n=85)$ used alcohol. $86.5 \%$ of smokers $(n=148)(p<0.001)$ and $91.8 \%$ of alcohol users $(n=78)(p<0.001)$ were male. Alcohol use was more frequent in the advanced age group $(\mathrm{p}=0.028$; median age in users 51.0). HCC was found at a higher rate in smokers $[29.8 \%$ of the smokers $(n=51) ; p=0.015$, odds ratio (OR): $2.1(1.1-3.8)]$. On the other hand, a significant correlation was not found between alcohol use and HCC $(p=0.351)$. While a significant correlation was not found between smoking and metabolic and biliary complications, metabolic complications were found in $63.3 \%$ of the alcohol users $(n=110)$ [ $p=0.033$; OR: $1.7(1.0-2.7)]$. Lifestyle incompliance was significantly higher following transplantation $[\mathrm{p}=0.044$; OR: $1.6(1.0-2.8)]$ in $57.6 \%$ of the patients using alcohol before transplantation $(n=49)$.

\section{Developmental Level of the Places Born-lived}

Distribution of liver transplant recipients according to the places where they were born and lived is shown in Fig. 1. When the places where the patients were born and lived were evaluated according to developmental level, all of the patients who were born in places with less development (level 4-5) lived in developed places (Fig. 2).

Finally, after separating developmental status data of the places where individuals were born and lived into groups of 2 as low and high, they 
Table 1. Correlation between the SES of the individuals and SES of places born and lived

\begin{tabular}{lllll}
\hline & \multicolumn{2}{l}{ Hollingshead index } & Total & $\mathbf{p}$ \\
\cline { 2 - 3 } & Low & High & & \\
\hline Birth place & & & & \\
$\quad$ Low & 125 & 24 & 149 & \\
$\quad$ High & 91 & 38 & 129 & 0.008 \\
Total & 216 & 62 & 278 & \\
Place lived & & & & \\
$\quad$ Low & 87 & 16 & 103 & \\
$\quad$ High & 129 & 46 & 175 & 0.038 \\
Total & 216 & 62 & 278 & \\
\hline
\end{tabular}

were compared with socioeconomic status data belonging to individuals whose Hollingshead indices were calculated. Comparative data are shown in Table 1. A statistically significant correlation was found between the SES of individuals and the developmental level of the places born and lived ( $\mathrm{p}=0.008, \mathrm{p}=0.038$, respectively).

\section{Social Security Status}

Liver transplant recipients were divided into three groups according to their social security status:

1. Status: with no social security, green card holder or uses the health insurance of a relative [104 patients $(37.4 \%)$ ].

2. Status: Social security institution and social security organization for artisans and self-employed [137 patients (49.3\%)].

3. Status: Retirement fund [37 patients (13.3\%)].

It was noted that women had significantly lower rates of social security than men $(\mathrm{p}<0.001)$.

\section{Etiologic Causes}

Seventeen different etiologic diseases were found as causes of primary disease in liver transplant recipients. Viral etiologies (67.3\%), Ethylism (7.2\%), Cryptogenic (11.2\%), Biliary tract pathologies (4.3\%), Fulminant Hepatitis (3.6\%), Metabolic Diseases (2.6\%), Autoimmune Hepatitis $(1.19 \%)$, Rare $(2.8 \%$ - Budd-Chiari Syndrome, insufficiency of the remaining liver tissue following surgery for hydatid cyst, liver metastasis of a neuroendocrine tumor, congenital hepatic fibrosis).

\section{Hepatocellular Carcinoma}

Before liver transplantation, HCC was present in $24.8 \%(n=69)$ of the patients. $84.1 \%$ of the cases with HCC were male and $15.9 \%$ were female $(\mathrm{p}=0.001)$. When cases were evaluated regarding age, cases with $\mathrm{HCC}$ were found to be older (median age of those without HCC 47, with HCC 52; $<$ 0.001). When patients were evaluated concerning prognostic scores, the MELD score was significantly lower in the patients with HCC (median MELD score in the patients with HCC 12, without HCC $16 ; \mathrm{p}<0.001)$. The rate of $\mathrm{HCC}$ was significantly higher in patients born in places with low developmental status $[\mathrm{p}=0.026$; OR: 8 (confidance interval (CI): 1.0-3.3)]. Rate of complications developing after transplantation was significantly higher in cases known to have HCC (complications were noted in $94.2 \%$ of patients with HCC; $\mathrm{p}=0.041$; OR: 2.9 (1.0-8.6)). Significantly correlated complications were neurologic (OR: $1.9 \mathrm{CI}$ : $1.0-3.6$; $\mathrm{p}=0.035)$, cardiac (OR: $2.1 \mathrm{CI}$ : 1.1-3.8; $\mathrm{p}=0.011$ ) and gastrointestinal (OR: $2.0 \mathrm{CI}: 1.1-3.7 ; \mathrm{p}=0.011$ ) complications. Work activity significantly decreased after transplantation in $71 \%$ of the patients with HCC ( $\mathrm{p}=0.013$; OR: $2(1.1-3.7)$ ).

\section{Data about the Operation}

The median duration of the liver transplantation surgery was 400 (140-960) minutes. The duration of surgery was significantly longer in transplantations performed from live donors $(\mathrm{p}<0.001)$. Similarly, in the analysis between operation time and cold ischemia time using the Kruskal-Wallis test, grouped cold ischemia time was significantly correlated with the operation time (operation time longest in those with cold ischemia time $<210$ minutes; $\mathrm{p}<0.001)$. Re-perfusion syndrome was noted in $6.8 \%(n=19)$ of the patients. Operation time was significantly longer in patients with the re-perfusion syndrome $(\mathrm{p}=0.034)$.

\section{Donor Data}

In this study, $69.4 \%$ of the donors $(n=193)$ were male and $30.6 \%(n=85)$ were female. Those with female donors had significantly higher rates of preservation damage $(66.7 \%)$ compared with those with male donors $(33.3 \%)(\mathrm{p}=0.026)$. Median donor age was $32(12-78$ years) and cadaver donors were significantly older $(\mathrm{p}<0.001)$. Of the donors, $55 \%(\mathrm{n}=153)$ were live donors and $45 \%(\mathrm{n}=125)$ were cadaveric donors. 1-year survival rates of total transplantations performed between 2006 and 2011 were $78.4 \%(n=98)$ in cadaveric donors and $76.4 \%$ in live donors $(n=117)$.

\section{Patient Follow-up Follow-up}

Median follow up values were 46.7 (0-89.3 months), 1400.5 (0-2679 days). In the patients that died, the median follow up values were 1.1 (0-72 months), 32.0 (0-2163 days). Analyses carried out between follow up time and other data showed that a high developmental level of the places resided by the patients significantly prolonged follow up time and this was independent of the places of birth or socioeconomic status of the individuals [place with a high developmental level 40.2 (0-89.3 months), 1205 (0-2679 days); $\mathrm{p}=0.05$ ].

\section{Complications}

The most frequently seen complications were metabolic complications with $59.4 \%(n=165)$, and the most frequently seen metabolic complications were impaired renal function (RF) tests and electrolyte imbalances with $76.6 \%(n=127)$.

\section{Immunosuppressive Drugs}

Patients who underwent liver transplantation used 17 different immunosuppressive drugs and their combinations. Drugs or their doses were changed in $11.5 \%(n=32)$ of the patients due to drug adverse effects or inefficacy. Adverse effects were in the form of RF and electrolyte disorders $[5.4 \%(n=15)]$, toxicity in the skin and adnexal places $[1.8 \%$ $(n=5)]$ and gingival hyperplasia $[0.7 \%(n=2)]$. Drugs were inefficient in $3.6 \%(n=10)$ of the patients. Rejection was significantly more common in patients using cyclosporine $[(15.3 \%(n=15)]$ compared with the patients not using it [p=0.050; OR: 2.1(1.0-4.6)]. 
Table 2. Correlation of the patient compliance with the developmental level of the places born and lived

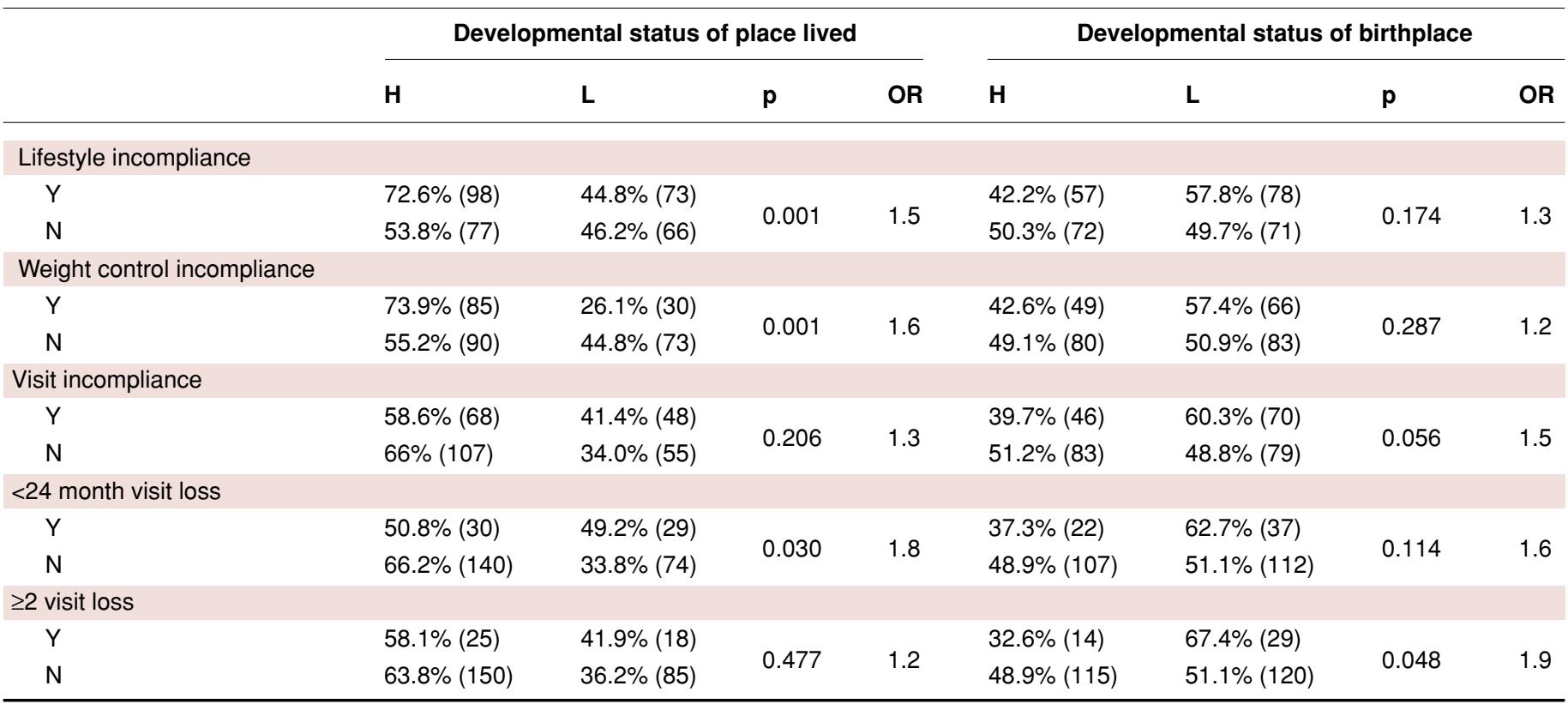

\section{Recurrence of Hepatitis}

Recurrences were recurrence of hepatitis B virus (HBV) and hepatitis $\mathrm{C}$ virus (HCV). In only one case, primary biliary sclerosing cholangitis signs were seen to recur after transplantation. Hepatitis recurrences were analyzed in two groups as recurrences with seropositive pathologic diagnosis and recurrences with a seronegative pathologic diagnosis. According to this division, the seropositive group was seen at a rate of $9.4 \%(n=26)$ and the seronegative group at $2.9 \%(n=8)$. Of the 26 seropositive cases, $76.9 \%(\mathrm{n}=20)$ had $\mathrm{HCV}$ and $23.1 \%(\mathrm{n}=6)$ had HBV.

\section{Patient Compliance}

Drug, control visit and lifestyle incompliances and decreased work activity were analyzed under the heading of general patient incompliance. Incompliance was noted in 190 patients and in $66.3 \%$ of males $(n=126)$ and $33.7 \%$ of women $(n=64) ;(p=0.285)$. The correlation between patient compliance and the developmental level of the places where patients were born and lived was analyzed and significant data are shown in Table 2. No significant correlation was found between patient compliance and rejection $(\mathrm{p}=0.886)$.

\section{Educational Status}

Liver transplant recipients consisted of 23 illiterate patients $(8.3 \%)$, 140 elementary school graduates $(50.4 \%), 38$ middle school graduates (13.7\%), 47 high school graduates (16.9\%), 19 vocational school graduates $(6.8 \%)$ and 11 university graduates $(4.0 \%)$ in a total of six groups.

\section{Vocational Status}

Occupations of the recipients were analyzed before grouping them. Accordingly, $55(19.8 \%)$ were housewives, $56(20.1 \%)$ were freelancers, $55(19.8 \%)$ were laborers, $16(5.8 \%)$ were civil servants, $14(5.0 \%)$ were teachers, $26(9.4 \%)$ were farmers, $8(2.9 \%)$ were drivers, $6(2.2 \%)$ were tradesmen, $5(1.8 \%)$ were engineers and $35(13.3 \%)$ were other professionals.
Identified occupations were later classified into major occupational groups designated by the Turkish Statistical Institution. A significant difference was not found between vocational status and gender ( $\mathrm{p}=0.061$ ). Similarly, data about graft and patient survival, patient compliance and complications concerning educational and vocational status in the follow up of liver transplant recipients are shown in Table 3.

\section{Socioeconomic Status of the Patients}

Socioeconomic status (SES) was assessed using the HI calculated with the educational status and occupational group data. Accordingly, the patients were divided into four categories as having a $\mathrm{HI}$ of $<21$ : 183 patients (65.8\%), of 21-34: 33 patients (11.9\%), of 34-48: 27 patients $(9.7 \%)$ and of $\geq 48: 35$ patients $(12.6 \%)$. The first two groups had low SES, and the last two groups had high SES. In addition, the correlation between SES and graft and patient survival, patient compliance and developing complications are shown in Table 4.

\section{Rejection}

While only clinical rejection developed in $19.4 \%$ of the patients $(\mathrm{n}=54)$, pathologic rejection was seen in $4.0 \%(\mathrm{n}=11)$ and clinicpathologic rejection in $9.3 \%(n=26) .50 \%$ of the patients with rejection were male $(n=13)$ and $50 \%(n=13)$ were female. Median time to the development of clinic-pathologic rejection was 186.5 (1-1198) days. The latest rejections occurred in patients with ethylism $(695 \pm 174$ days) and the earliest rejections developed in patients transplanted for cryptogenic liver failure (9.0 days) $(\mathrm{p}=0.019)$. Rejection occurred early in the patients with prolonged cold ischemia time ( $>540 \mathrm{~min}-$ utes) (34.0 days), and in those with cold ischemia time $(<210 \mathrm{~min}-$ utes), rejection developed later $(553.5 \pm 103$ days $)(\mathrm{p}=0.001)$. Median age of the patients developing rejection was 49 years (26-61). BMI of patients developing rejection was between 25 and 29.9 in $55.2 \%$ $(n=16)$ (Table 5). 
Table 3. Data about patient and graft survival, patient compliance and complications concerning educational and vocational status in liver transplant recipients

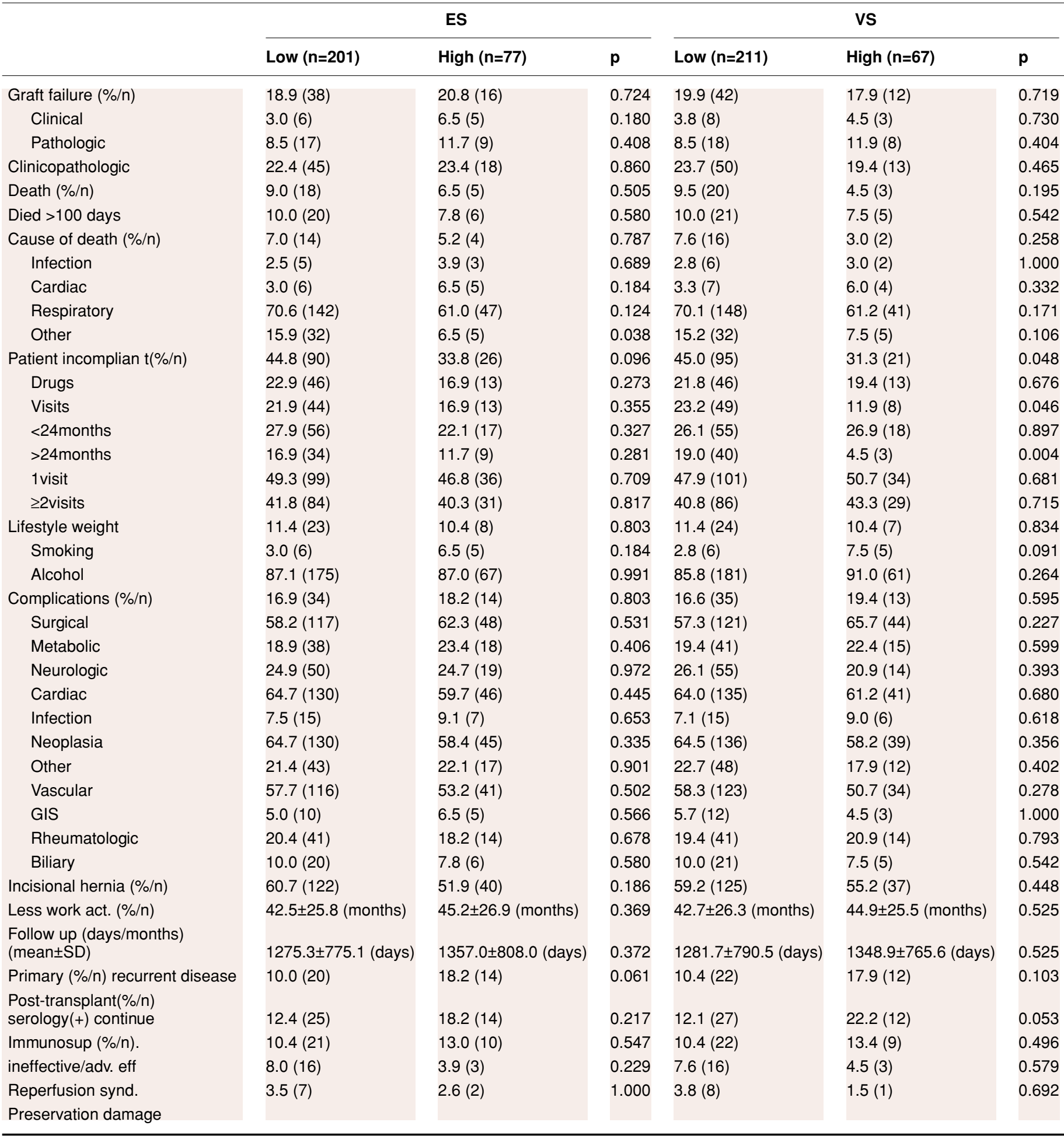

\section{Death}

During the post-transplant follow up, $22.7 \%(n=63)$ of the patients died. $63.4 \%$ of the deaths $(\mathrm{n}=40)$ occurred within the first 100 days and $75 \%$ of them $(n=30)$ occurred in the first month. $74.6 \%(n=47)$ of the patients who died were male and $25.4 \%(n=16)$ were female. On the other hand, there was no significant difference in the death rates concerning years $(\mathrm{p}=0.364)$. When the correlation between causes of liver failure and death was evaluated, $23.8 \%(n=15)$ of the patients who died underwent transplan- 
Table 4. Data about the correlation between SES and patient and graft survival, patient compliance and complications in liver transplant recipients

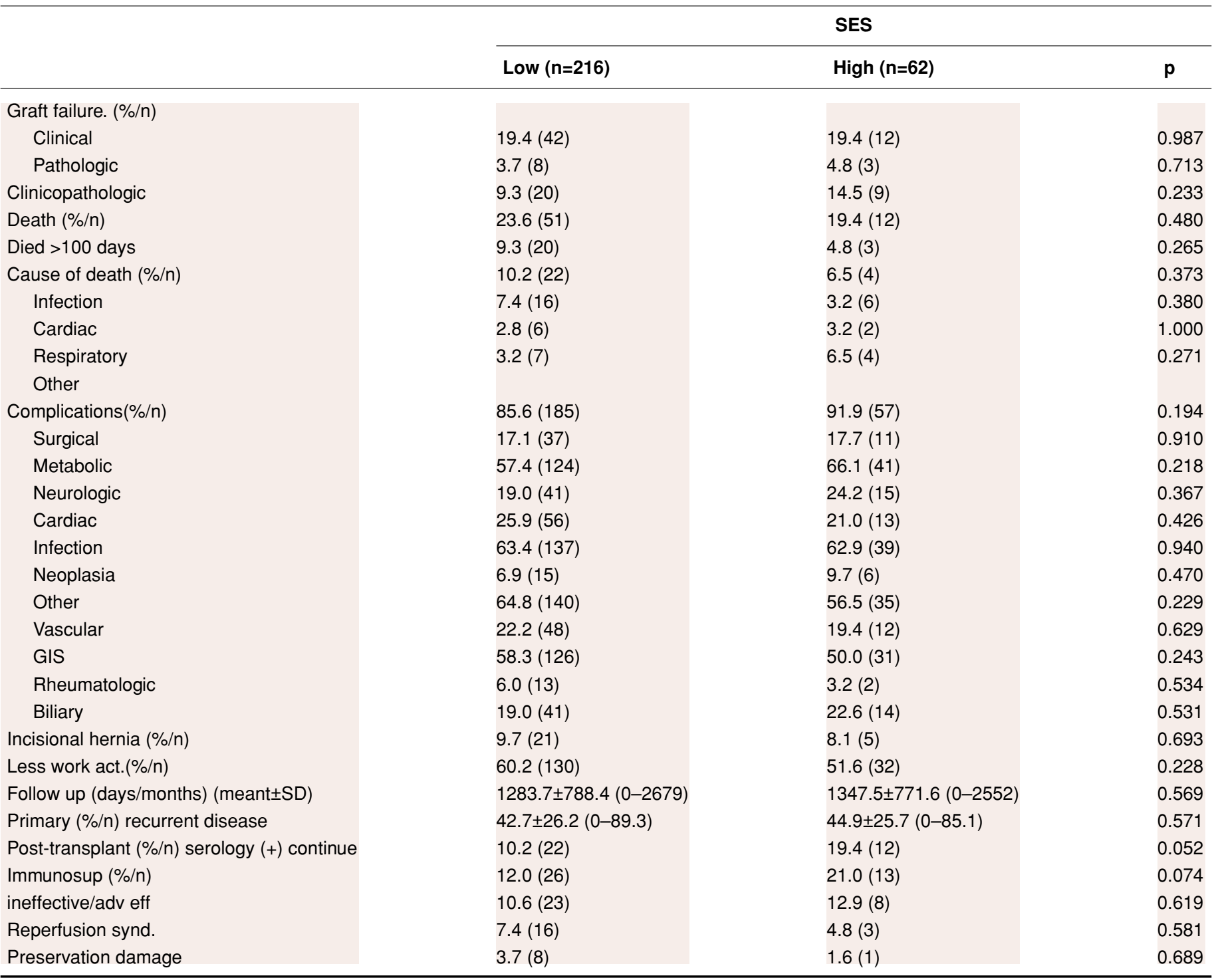

tation because of HCV-related liver failure, whereas this rate was $12.6 \%$ $(\mathrm{n}=27)$ in the patients that survived $(\mathrm{p}=0.028$; OR: $2.1(1.0-4.4))$. This correlation was exactly reversed in the case of delta hepatitis, where delta hepatitis was seen in $12.7 \%(n=8)$ of deaths and in $26.5 \%(n=57)$ of the patients who survived $(\mathrm{p}=0.023$; OR: $0.4(0.1-0.8)$ ). Comorbid diseases were seen in $71.4 \%(n=45)$ of the patients who died $[p=0.008$; OR: $2.2(1.2-4.1)]$. There was no significant correlation between death and education $(p=0.860)$, vocation $(p=0.465)$ and SES $(p=480)$. The immunosuppressive drug most frequently used by the patients who died was cyclosporine $[47.6 \%(n=30)][p=0.019$; OR: $1.9(1.1-3.4)]$. Death was noted at a higher rate in the patients with preservation damage with a rate of $7.9 \%(n=5)[p=0.031$; OR: $4.5(1.1-17.4)]$. The most frequent cause of death was infections $[41.2 \%$ of deaths $(n=26)]$.

\section{Survival Analyses}

According to the Kaplan-Meier survival analysis of liver transplant pa- tients, the mean expected survival was 70.3 months (66.1-74.4 months), and the survival rate was $77.3 \%$. 6-month survival rate was $85.3 \%$, the 1 -year survival rate was $83.1 \%$, and the 2 -year survival rate was $80.9 \%$. In men, expected survival was 68.5 months, and the survival rate was $75.3 \%$. In women, the mean survival was 73.7 months, and the survival rate was $81.8 \%$; there was no significant difference regarding gender $(\mathrm{p}=0.251)$. The expected survival was significantly shorter in advanced age $(\mathrm{p}=0.003)$. The duration and rate of expected survival were noted to be higher in those with BMI $\geq 30$ compared with the other two groups $(\mathrm{p}=0.208)$. (Mean expected survival of 5 patients with BMI $\geq 30$ was 78.6 months and the rate of survival was $88.1 \%$ ). When the relation between comorbid diseases and survival was analyzed, the expected duration and rates of survival were seen to be significantly higher in those without comorbid diseases than in the patients with comorbid diseases $(76.5$ months and $85 \%$ in the patients without comorbid diseases; $\mathrm{p}=0.011)$. The expected duration and rate of survival were significantly shorter in patients with nephropathy. 
Table 5. Data with significant correlation with rejection

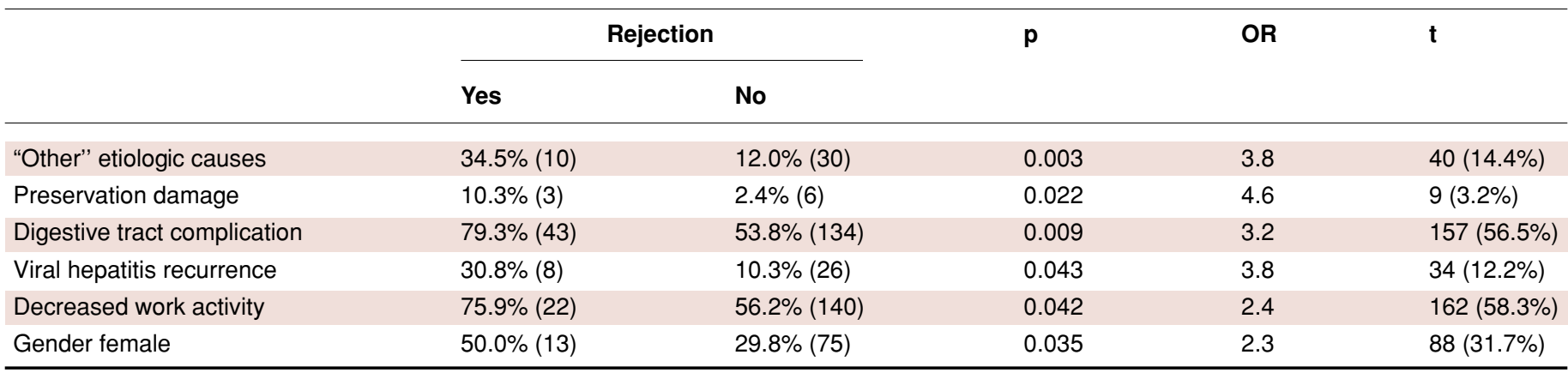

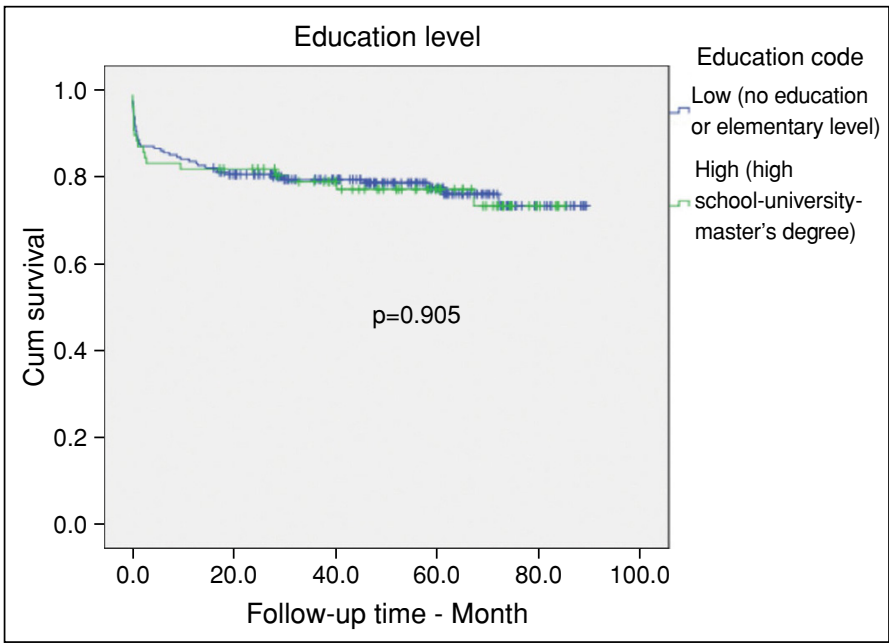

Figure 3. Survival curve concerning education level.

The expected survival was 56.7 months and the rate was $60.9 \%$ in the patients with nephropathy $(\mathrm{p}=0.049)$.

Correlation between causes of liver failure and survival was analyzed, and the expected duration and rate of survival were significantly less in patients undergoing transplantation because of HCV-related liver failure (59.3 months and $64.3 \% ; \mathrm{p}=0.041)$. No significant difference was found in survival analyses performed regarding educational status, vocational status, developmental level of the places born and lived and SES (Fig. 3, 4).

The expected duration and rate of survival were significantly lower in the patients using cyclosporine (63.2 months; survival rate $69.4 \%$; $\mathrm{p}=0.015$ ). The duration and rate of survival were significantly less in patients with reservation damage (28.4 months; survival rate $44 \%$; $\mathrm{p}=0.006$ ). Among the metabolic complications, the expected duration and rate of survival were significantly less in patients with RF and electrolyte disorders (RF-e) (51.4 months and 55.9\%; $\mathrm{p}<0.001)$. The expected duration and rate of survival were significantly less in patients with infectious complications (63.1 months; 71.3\%; $\mathrm{p}=0.001)$. Among pulmonary infections, fungal pneumonia had the lowest survival rate (survival rate of $16.7 \%$ ).

The expected duration and rate of survival were significantly less in the patients with vascular complications (49.3 months; 53.3\%; $<<0.001$ ). When subtypes of vascular arterial complications were analyzed concerning survival, the expected survival was 37.1 months and survival rate was $40 \%$ in arterial thrombosis, survival was 50.2 months and sur-

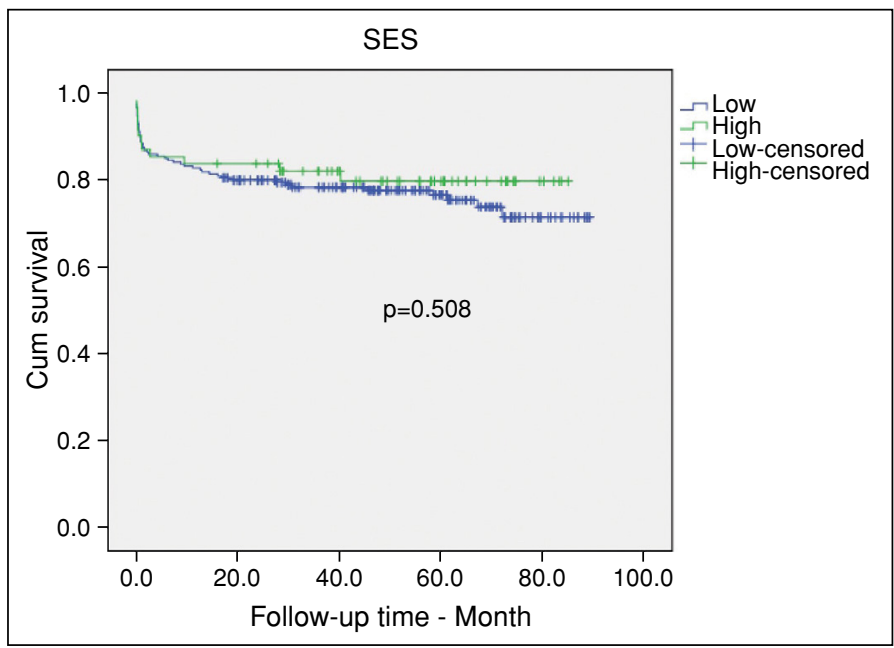

Figure 4. Survival curve concerning SES.

vival rate was $66.7 \%$ in arterial stenosis or insufficiency and survival was 9.4 months and survival rate was $10 \%$ in hemorrhagic complications $(\mathrm{p}<0.001)$.

\section{Discussion}

With advanced surgical techniques, improved postoperative care and the introduction of new immunosuppressive drugs, liver transplantation has become the most effective treatment method for end-stage liver disease patients. In addition to the prolonging survival of many patients, liver transplantation requires long term close follow up and care because of many factors affecting graft or patient survival. ${ }^{[13]}$ Currently, there are not sufficient organs obtained from cadavers to meet the increasing number of patients with liver failure almost in all countries. Under the present conditions, patient selection, the timing of the transplantation and post-transplant patient follow up are vital for the planning of an effective organ distribution. ${ }^{[14]}$

Patient incompliance is an important cause of rejection and graft loss. Educational and socioeconomic status of the patients has been associated with the delayed application for transplantation, difficulties in the management of post-transplant patients and incompliance with medical therapy. In the study of Yoo et al. ${ }^{[15]}$ education was found to have a marginal effect on the outcomes. In the study, the survival of high school graduates was found to be lower than that of university graduates. While the survival of individuals with private insurance was better than that of the individuals with state insurance, African Americans 
had lower rates of 5-year survival than white Americans when SES and other factors affecting survival were excluded.

Obesity can be seen in approximately $20 \%$ of the patients following liver transplantation. ${ }^{[16]}$ Although there are publications in the literature reporting that obesity-associated mortality increases following transplantation, there are also studies reporting that it does not have an important contribution to mortality. ${ }^{[17-19]}$ In our study, BMI was also significantly higher in patients with complications. In addition, patient compliance was found to be less in patients with high BMI and that this condition was due to the inability to control weight in lifestyle incompliance. On the other hand, lifestyle incompliance (particularly diet incompliance) was more in the patients living in developed places.

In our study, $28 \%$ of the patients who died after transplantation had comorbidities, and $15.0 \%$ did not have comorbid diseases. Regarding the correlation between comorbid diseases and survival, the expected duration and rate of survival were found to be significantly higher in the patients without comorbid diseases. In the study of Wasilewicz et al. ${ }^{[20]}$ analyzing the effects of comorbidities in the post-transplantation period on survival in liver transplant patients, 23 of 169 patients $(14 \%)$ were lost within the first one month. Fifty-one patients had at least one comorbid disease, but there was no statistical difference between patients who survived and died regarding the effects of comorbidities on survival.

In Yoo et al.' ${ }^{[15]}$ study carried out on liver transplant recipients, patients living in the United States were classified according to the income status of the places they resided depending on their postal code and found that this had an impact on their survival. In our study, visit incompliance during the first two years was found at a higher rate in those living in places with low developmental status, and the most frequent causes were distance to the transplantation center and poor economic status. Similar to the results of our study, a marked correlation was found between patient incompliance and low SES in liver transplant recipients. ${ }^{[21]}$

In our country, health insurance is state-sponsored at a high rate. The presence of health insurance also influences patient compliance. In our study, patients with low category health insurance had higher visit incompliance. In the study carried out by Yoo et al. ${ }^{[15]}$ on liver transplant recipients in the US, health insurance was divided into five categories according to the system present in the country and its effect on survival was analyzed. The presence of private health insurance significantly affected their survival. Although a direct effect of health insurance level on survival could not be shown in our study, due to its significant correlation with visit incompliance, socioeconomic status and developmental level of the birthplaces, these factors should be kept in mind in the follow up of these patients. In addition, its effect on survival can be demonstrated in studies with longer follow up and a higher number of patients.

When the effects of etiologic causes on survival were analyzed, 12-month survival was significantly lower in the patients who underwent liver transplantation because of $\mathrm{HCV}$ compared with the patients who did not have HCV (73.8\% vs. 84.7\%; $\mathrm{p}=0.041)$, whereas 12 -month survival was significantly higher in patients undergoing liver transplantation because of delta hepatitis $(93.8 \%$ vs. $79.8 \%$; $p=0.023)$. In the prospective study performed by Gambato et al. ${ }^{[22]}$ entitled the effects of donor and recipient data on the outcomes, the effects of liver failure cause on patient and graft survival were analyzed. Similar to the data mentioned in our study above, HCV was reported to be seen at an advanced age and to markedly decrease survival, but no results were reported regarding delta hepatitis. In this study, which was performed in Italy, 34\% of the patients who underwent liver transplantation had HCC and $\mathrm{HCV}$ was the most common etiologic disease (40\%) that was associated with $\mathrm{HCC}$ in this study. A significant correlation was not found between survival and HCC. While the median MELD value was higher in the patients without tumors, the median MELD value was lower in the cases with HCC, as was expected. Similar results were also obtained in the correlation analysis performed in our study between HCC and MELD and survival. While no effect of HCC was found on cumulative survival, interestingly, the same rates were found for median MELD values. In addition, in our study, we also found the correlation of Child score with HCC, which is outside MELD as a prognostic scoring system. Different from the study of Gambato et al. ${ }^{[22]}$ the etiologic disease that showed the highest rate of association with HCC was HBV in our study and this association significantly increased HBV-related HCC by 3.7-fold. This difference in the association of HCC with hepatitides may be because chronic HCV infection has become the most frequent agent in patients with chronic hepatitis, liver failure, hepatocellular cancer development and patients requiring liver transplantation because of regular immunization programs conducted against $\mathrm{HBV}$ in western societies. ${ }^{[23]}$

In our study, it was found that complications developed in $95.7 \%$ of the patients with HCC who underwent liver transplantation and the presence of HCC significantly increased the development of complications by 2.9-fold. Complications found to be significantly correlated were neurologic, cardiac and gastrointestinal complications. In the study by Yong Lei et al. ${ }^{[24]} 10$ complications were found in 31 of the 102 patients with HCC who underwent transplantation and the severity of complications was also reported. These complications were biliary leakage, intra-abdominal hemorrhage, wound site infection, pleural effusion, respiratory failure, ileus, thrombosis of the hepatic artery, subphrenic abscess, liver failure and rejection. In our study, at least one complication developed in $88.5 \%(\mathrm{n}=246)$. While the most frequent complications were metabolic complications, with a rate of $59.4 \%$, impaired RF and electrolytes were the most frequent metabolic complications, with a rate of $76.6 \%$. The rates of acute renal failure after liver transplantation were reported between $40 \%$ and $70 \%$ in various studies. ${ }^{[25]}$

Median donor age was 32 years, and a significant correlation was not found between patient and graft survival and donor age. In a study performed in Spain and analyzing the effects of donor age on patient and graft survival, donors aged 60 years and above were included and it was seen that advanced donor age did not have an effect on patient and graft survival. ${ }^{[26]}$ In our study, there were no differences in 1-year survival rates of recipients in terms of donor type in the total transplantations performed between 2006 and 2011. In another study examining the effects of live and cadaveric donors on patient and graft survival, no differences were noted concerning patient survival, whereas graft survival was significantly shorter in transplantations from live donors. ${ }^{[27]}$

The most frequently used immunosuppressive combination in our center was cyclosporine + mycophenolate mofetil combination, while in the study of Loeches et al. ${ }^{[28]}$ this was tacrolimus + mycophenolate mofetil. The most frequent adverse effect of frequently used cyclosporine and tacrolimus is nephrotoxicity ${ }^{[15]}$ Similarly, RF and electrolyte disorders were also the most frequent adverse effects related to immunosuppressives in our study.

While the recurrence of primary disease after transplantation is most frequently related to hepatitis B in our country, it is related to hepatitis C in the US and Europe. ${ }^{[2]}$ Contrary to our expectations, the recurrence of 
primary disease was most frequently related to hepatitis $\mathrm{C}$ in our study (76.9\%). This was attributed to the administration of immunoglobulins to all patients with hepatitis B after transplantation and the use of new antivirals against lamivudine resistance.

In our study, at least one of the drugs, visit and lifestyle incompliances were present in 190 patients. Lifestyle incompliance was encountered the most. Work activity decreased in 162 of 190 patients. Weight gain was most common in lifestyle incompliance. Patient compliance did not have any significant effect on graft and patient compliance. However, low levels in parameters, such as educational, vocational status and SES, were found to be correlated with patient compliance. Drug incompliance was more in the patients with low educational status; visit incompliance was more in the patients with low vocational status and visit incompliance was more in the patients with low SES. Therefore, if studies with a higher number of patients and longer follow up are performed, taking these factors into account in the patient selection and follow up, effects on patient and graft survival can also be shown.

In our study, no significant correlation was found between SES and factors affecting patient and graft health like patient survival, the recurrence of primary disease, drug adverse effects and inefficacy, complications, rejection and death. While there are studies in the literature about the effects of SES on patient and graft survival, there are also studies showing that it has no effect. In the study of Yoo et al. from Johns Hopkins University evaluating 276 patients about the effects of socioeconomic status on the results of liver transplantation, socioeconomic status was determined using the HI used in the manner that it was used in our study. In this study, patient and graft survival were compared with the four groups determined with the Hollingshead index, and SES was found to be ineffective on patient and graft survival. ${ }^{[30]}$ In the research conducted by Gruttadauria et al. ${ }^{[14]}$ in Italy, educational status was found to be effective on patient survival. The analysis revealed that high educational level decreased post-liver transplantation deaths by 0.6 -fold and high SES by 0.1 -fold, and Kaplan-Meier survival analysis revealed a significant correlation with education and SES. There are limitation factors for both studies. The groups in the HI of the first study were determined randomly as quartiles and may not reflect real-life social characteristics. In addition, the insufficient number of patients and follow up may have affected study outcomes in the first study. On the other hand, SES was not grouped appropriately in the second study. SES was grouped only according to occupations in this study and occupational characteristics were not determined in sufficient scales to reflect real society. Occupational groups were stratified as an unoccupied, housewife, qualified-unqualified workers and managers, and were classified as low and high according to this. Likewise, the number of patients and follow up of this study may not be adequate.

In our study, the rate of rejection was $9.3 \%$ in liver transplant patients. Rates of acute rejection following liver transplantation are given as $25 \%-30 \%$ in the literature. ${ }^{[31]}$ Among etiologic diseases, ethylism took the longest time for rejection to occur and the earliest rejection occurred in patients who underwent transplantation because of cryptogenic liver failure. Cold ischemia time was inversely proportional to the time to rejection and prolonged cold ischemia time was associated with early rejection. It was shown in a study that cold ischemia time caused rejection by increasing the risk of hepatic artery thrombosis. ${ }^{[32]}$ Other factors associated with rejection were other etiologic causes, preservation damage, digestive tract complications, and recurrence of viral hepatitis and decreased work activity. The risk of the rejection was increased 3.8-fold in patients undergoing transplantation as a result of liver failure due to other etiologic causes. In a study analyzing the risk factors for chronic rejection in patients undergoing liver transplantation, the rejection was found at higher rates in patients undergoing transplantation because of liver failure due to other etiologic causes compared with the viral hepatitis group. ${ }^{[33]}$ The rejection rate of the graft increases with the severity of preservation damage. In the study of Howard et al., ${ }^{[34]} \mathrm{a}$ positive correlation was shown between preservation damage and acute cellular rejection. In our study, preservation damage increased the odds of rejection 4.6-fold, and it increased 3.2-fold in those with digestive tract complications. It was found that the possibility of rejection increased 3.8-fold in patients with recurrent viral hepatitis after transplantation, and the highest rejection rate was seen in patients with recurrent HBV. HBV re-infection usually develops in the first six months after the transplantation. Decreased work activity increased 2.4-fold in the patients developing rejection compared with the patients who did not. This was thought to cause a decrease in the work activity of patients because of frequent outpatient visits and hospital admissions caused by rejection induced clinical and laboratory signs.

The rate of mortality was $22.7 \%$ in our study. Deaths were seen most frequently in the first month. One-year survival rates of total transplantations performed between 2006 and 2011 according to donor type were $78.4 \%$ in cadavers and $76.4 \%$ in live donors. On the other hand, $73.5 \%$ of a total of 1001 transplantations performed by 2012 in our country were from live donors and the mortality rate was $15.7 \%$, whereas $26.4 \%$ were transplanted from cadavers and mortality rate was $19.2 \%$. In the study performed by Weber et al. ${ }^{[35]}$ in the US, the presence of nephropathy before and after transplantation was associated with severe mortality and morbidity. They stated that it is important to evaluate nephropathy before transplantation because in the case of a severe renal failure before transplantation, transplantation of both kidney and liver, which are rather difficult to obtain, will be required. They also stated that evaluation of renal insufficiency by testing for creatinine level only before transplantation would not be right, and evaluating for a hepatorenal syndrome, which has high mortality, particularly during this period, is important regarding the prevention of mortality. Similarly, $8.3 \%$ of the patients in our study had nephropathy and the rate of RF and electrolyte disorders after transplantation was increased 3.9-fold in $73.9 \%$ of these patients. The presence of nephropathy before transplantation increased the odds of mortality 2.2-fold. The complication of nephropathy developing after liver transplantation is almost a rule. Its most important cause is the toxicity of cyclosporine or tacrolimus used as immunosuppressives. Renal ischemia occurring during the anhepatic period, hypotension, and other nephrotoxic drugs may cause renal failure. While the complication of nephropathy developing after transplantation causes a 16.7-fold increase in the possibility of mortality, nephropathy rate was highest in patients using steroids with calcineurin inhibitors like tacrolimus or cyclosporine.

In the 4000-case series of Pittsburgh University published in 2000, 1-, 5 -, 10 - and 15 -year survival rates were $79 \%, 67 \%, 57 \%$ and $50 \%$, respectively. The most important cause of mortality in this series was an infection, with a rate of $28.4 \%{ }^{[29]}$ Similarly, the most frequent cause of mortality was an infection in our study (41.2\%). Although the most frequent cause of death was an infection, the complications that caused mortality at a higher rate when they occurred were cardiac and metabolic complications, and infections caused a 2.8 -fold increase in the possibility of mortality. While pulmonary infection-induced mortality was the most frequent among infectious diseases (69.8\%), the infectious disease that increased the odds of mortality at the highest rate was 
a hematologic infection. Among pulmonary infections, bacterial infections caused mortality most frequently $(43.0 \%)$, and the pulmonary infection with the highest rate of mortality was fungal pneumonia. Similarly, it has been reported in the literature that bacterial infections make up $50 \%-60 \%$ of all infections in transplant patients, and fungal infections were severe infections with high mortality. ${ }^{[29]}$

The limitations of our study were patient number and duration of follow up, as well as the HI used for calculating SES. The limitations of the HI were the exclusion of factors other than education and occupation that can affect SES and obtaining results different from actual SES because of the random grouping of the results into quartiles. To our knowledge, there is not any research about this subject in our country and there are also very few studies in the literature, which remained under-researched. However, our study is the study with the highest number of patients among the studies available in the literature. If studies with longer follow up and a higher number of patients are designed, more significant results can be obtained about the subject.

\section{Conclusion}

Liver transplantation is the only treatment modality of end-stage liver disease. The most important problem of liver transplantation performed at increasing rates in multiple centers is obtaining sufficient donors and this problem is not predicted to be surpassed in the near future. Therefore, in addition to performing organ transplantations to suitable recipients at a suitable time with the available means, determining a follow-up and treatment plan depending on the characteristics of the patients beforehand is also important for the success of transplantations. Socioeconomic status and educational level of patients are the determining characteristics of patient compliance that affects the success of liver transplantation that can be predicted before transplantation. In our study, we also analyzed other factors thought to affect patient and graft survival, primarily socioeconomic and cultural status and educational level. These factors were parameters like demographic data of the patients, developmental level of the places born and lived, health insurance status, surgical data, adverse effects of the immunosuppressive drugs used, and complications developing during patient follow up after transplantation, the recurrence of primary disease and patient compliance. Although a direct effect of SES on patient and graft survival could not be shown, other than patient and graft survival, vocational and educational status that determine SES should be considered before the transplantation and during follow up of patients because of their significant correlation with parameters that may affect success of the liver transplantation like etiologies of liver failure, comorbid diseases, history of alcohol use, developmental level of the places born and lived, social security status, and drug and visit incompliance.

Ethics Committee Approval: This study was approved by the Dokuz Eylul University Ethics Committee on September 27, 2012 (approval number 2012/31-01).

Peer-review: Externally peer-reviewed.

Author Contributions: Arif Hakan Onder, Goksel Bengi, Mucahit Ozbilgin, Tarkan Unek, Ibrahim Astarcioglu and Mesut Akarsu contributed equally to this work, designed the research, drafted the manuscript and provided administrative and technical support.

Conflict of Interest: The authors have no conflict of interest to declare.

Financial Disclosure: The authors declared that this study has received no financial support.

\section{References}

1. Moreno R, Berenguer M. Post-liver transplantation medical complications. Ann Hepatol 2006;5:77-85.

2. Sağlık Bakanlığı Sağlık Bilgi Sistemleri Genel Müdürlüğü. Sağlık İstatistikleri Yıllığg 2012. Available from: https://sbu.saglik.gov.tr/Ekutuphane/ Yayin/459. Accessed August 31, 2013.

3. Anadolu Ajansı. Organ bekleyen hasta sayısı artiyor. Available from: https:// www.aa.com.tr/tr/saglik/organ-bekleyen-hasta-sayisi-artiyor/311833. Accessed August 31, 2013.

4. Abbasoğlu O. Karaciğer transplantasyonu. In: İliçin G, Biberoğlu K, Süleymanlar G, Ünal S, editors. İç Hastalıkları. $3^{\text {rd }}$ ed. Ankara: Güneş Tıp Kitabevi; 2012. p. 1539-48.

5. Akdeniz Üniversitesi Prof.Dr.Tuncer Karpuzoğlu Organ Nakli Merkezi. Karaciğer Nakli. Available at: https://www.akdenizorgannakli.net/index. php/akdeniz-organ-nakli-merkezi-organ-nakilleri/akdeniz-organ-naklimerkezi-karaciger-nakli. Accessed August 31, 2013.

6. Dienstag JL, Raymond T. Chung Liver Transplantation. Editors: Harrison TR, Resnick WR, Wintrobe MM. Harrıson's Principles of İnternal Medicine. Ankara: Nobel Tip Kitapevi; 2013. p. 1983-90.

7. Keefe EB. Hepatic failure and liver transplantation. In: Goldman L, Ausiello D. Cecil Medicine. $23^{\text {rd }}$ ed. Ankara: Güneş Tıp Kitabevi; 2011. p. 1147-52.

8. Quintieri F, Pugliese O, Mattucci DA, Taioli E, Venettoni S, Costa AN. Liver transplantation in Italy: analysis of risk factors associated with graft outcome. Prog Transplant 2006;16:57-64.

9. Doyle HR1, Morelli F, McMichael J, Doria C, Aldrighetti L, Starzl TE, et al. Hepatic retransplantation an analysis of risk factors associated with outcome. Transplantation 1996;61:1499-505.

10. Türkiye İş Bankası. 2010 ve 2012 Verileriyle Türkiye'de İllerin Gelişmişlik Düzeyi Araştırması. Available at: https://ekonomi.isbank.com.tr/ContentManagement/Documents/ar_03_2012.pdf. Accessed August 4, 2013.

11. Türkiye İstatistik Kurumu. Uluslararası Standart Meslek Sınıflaması - ISCO 08. Available at: https://biruni.tuik.gov.tr/DIESS/SiniflamaSatirListeAction.do? surumId $=210 \&$ seviye $=1 \&$ detay $=$ H\&turId $=41 \&$ turAdi $=\% 209 . \% 20$ Meslek\%20Sinıflamaları. Accessed August 4, 2013.

12. Yoo HY, Galabova V, Edwin D, Thuluvath PJ. Socioeconomic Status Does Not Affect the Outcome of Liver Transplantation, Liver Transpl 2002;8:1133-37.

13. Kim WR, Poterucha JJ, Kremers WK, Ishitani MB, Dickson ER. Outcome of liver transplantation for hepatitis B in the United States. Liver Transpl 2004;10:968-74.

14. Gruttadauria S, Grosso G, Mistretta A, Pagano D, Scianna G, Vizzini GB, et al. Impact of recipients' socio-economic status on patient and graft survival after liver transplantation: The IsMeTT experience. Dig Liver Dis 2011;43:893-8.

15. Yoo HY, Thuluvath PJ. Outcome of liver transplantation in adult recipients: influence of neighborhood income, education, and insurance. Liver Transpl 2004;10:235-43.

16. Befeler AS, Di Bisceglie AM. Hepatocellular carcinoma: diagnosis and treatment. Gastroenterology 2002;122:1609-19.

17. Murray KF, Carithers RL Jr; AASLD. AASLD practice guidelines: Evaluation of the patient for liver transplantation. Hepatology 2005;41:1407-32.

18. Lidofsky SD. Liver transplantation for fulminant hepatic failure. Gastroenterol Clin North Am 1993;22:257-69.

19. Liermann Garcia RF, Evangelista Garcia C, McMaster P, Neuberger J. Transplantation for primary biliary cirrhosis: retrospective analysis of 400 patients in a single center. Hepatology 2001;33:22-7.

20. Wasilewicz M, Raszeja-Wyszomirska J, Wunsch E, Wójcicki M, Milkiewicz P. Modified Charlson Comorbidity Index in Predicting Early Mortality After Liver Transplantation. Transplantation Proceedings 2009; 41,3117-8.

21. Collins BH, Pirsch JD, Becker YT, Hanaway MJ, Van der Werf WJ, D’Alessandro AM, et al. Long-term results of liver transplantation in older pa- 
tients 60 years of age and older. Transplantation 2000;70:780-3.

22. Gambato M, Frigo AC, Rodríguez Castro KI, Senzolo M, Nadal E, D’Amico F, et al. Who Fares Worse After Liver Transplantation? Impact of Donor and Recipient Variables on Outcome: Data from a Prospective Study. Transplantation 2013;95:1528-34.

23. Cacoub P, Poynard T, Ghillani P, Charlotte F, Olivi M, Piette JC, et al. Extrahepatic manifestations of chronic hepatitis C. MULTIVIRC Group. Multidepartment Virus C. Arthritis Rheum 1999;42:2204-12.

24. Lei JY, Yan LN, Wang WT. Transplantation vs resection for hepatocellular carcinoma with compensated liver function after downstaging therapy. World J Gastroenterol 2013;19:4400-8.

25. Sözbilen M, Tokat Y, Organ Prezervasyonu. In: Gülay H, editor. Temel ve Sistematik Cerrahi. $1^{\text {st }}$ ed. İzmir: Güven Kitapevi; 2005. p. 631-45.

26. Urata K, Brault A, Rocheleau B, Huet PM. Role of Kupffer cells in the survival after rat liver transplantation with long portal vein clamping times. Transpl Int 2000;13:420-7.

27. Urata K, Brault A, Huet PM. Effects of portal vein clamping tim eon rat liver microcirculation following extended cold preservation and transplantation. Transpl Int 1999;12:408-14.

28. Loeches B, Valerio M, Pérez M, Bañares R, Ledesma J, Fogeda M, et al. BK Virus in Liver Transplant Recipients: A Prospective Study. Transplantation
Proceedings 2009;41:1033-7.

29. World Health Organization. Report on the Burden of Endemic Health CareAssociated Infection Worldwide. Available at: https:/apps.who.int/iris/ bitstream/handle/10665/80135/9789241501507_eng.pdf;jsessionid=1F2CCBD5634240792AC2E96299FCB310?sequence $=1$. Accessed December, 2010.

30. De Bleser L, Matteson M, Dobbels F, Russell C, De Geest S. Interventions to improvemedication-adherence after transplantation: a systematic review. Transpl Int 2009;22:780-97.

31. Sabate E. Adherence to Long-Term Therapies: Evidence for Action. Geneva, Switzerland: World Health Organization; 2003.

32. Laederach-Hofmann K, Bunzel B. Noncompliance in organ transplant recipients: a literature review. Gen Hosp Psychiatry 2000;22:412-24.

33. Rodríguez A, Díaz M, Colón A, Santiago-Delpín EA. Psychosocial profile of noncompliant transplant patients. Transplant Proc 1991;23:1807-9.

34. Cherubini P, Rumiati R, Bigoni M, Tursi V, Livi U. Longterm decrease in subjective perceived efficacy of immunosuppressive treatment after heart transplantation. J Heart Lung Transplant 2003;22:1376-80.

35. Hillingsø JG, Wettergren A, Hyoudo M, Kirkegaard P. Obesity increases mortality in liver transplantation--the Danish experience. Transpl Int 2005;18:1231-5. 